\title{
The interaction between people, information and innovation: information literacy to underpin innovative work behaviour in a Finnish organisation
}

\author{
Lyndsey Middleton \\ School of Computing, Edinburgh Napier University, \\ Scotland, UK, L.Middleton@napier.ac.uk \\ Hazel Hall \\ School of Computing, Edinburgh Napier University, \\ Scotland, UK, H.Hall@napier.ac.uk
}

\author{
Laura Muir \\ School of Computing, Edinburgh Napier University, \\ Scotland, UK, L.Muir@napier.ac.uk \\ Robert Raeside \\ The Business School, Edinburgh Napier University, \\ Scotland, UK, R.Raeside@napier.ac.uk
}

\begin{abstract}
Workplace learning and employee-led innovation are related. For example, mistakes made when learning may spur innovation. Investigated in this paper is the role of information literacy in the learning of innovative work behaviour in the workplace, and the associated information behaviours that allow for innovative work behaviour to develop. Thus interactions between people, information and innovation are a main focus. The findings derive from analysis of data generated in twelve semi-structured interviews conducted within a Finnish organisation. Employee perceptions on the role of information in the workplace, and its role in supporting the learning of innovative work behaviour, are explored. The analysis reveals that: (1) information literacy skills serve as a prerequisite for workplace learning; (2) information behaviours support the learning of innovative work behaviour and; (3) a variety of information sources support employees as they learn to behave innovatively.
\end{abstract}

\section{KEYWORDS}

workplace learning, innovative work behaviour, information literacy, information behaviour

\section{INTRODUCTION}

Information literacy has been considered an initiator of information behaviour applicable to workplace contexts since the 1990s (e.g. Bruce, 1999; Tait \& Edwards, 2016). In prior research the focus falls on its role in the building of skills (e.g. Crawford \& Irving, 2009) and generic workplace competencies (Banek Zorica, Spiranec, \& Biskupic, 2014). A few researchers only (among them Lloyd \& Somerville, 2006) have considered information literacy and associated information behaviours in respect of learning in the workplace. Most studies, in contrast, are conducted in educational settings such as schools (e.g. Adhikari, Scogings, Mathrani \& Sofat, 2017).

The relationship between workplace learning and innovation has also been investigated in prior studies (e.g. Høyrup, 2010). Here employee-led innovation, i.e. innovation developed at the level of individual employees rather than that of the organisational level, is the main focus. Ellström (2010) suggests that learning plays a central role such research. Høyrup (2010) makes this relationship explicit by conceptualising innovation processes as learning processes: learning is a mechanism that underpins employee-led innovation, e.g. like innovation, it is both practice-based and employee-driven (p.151). Høyrup also differentiates between innovation and innovative work behaviour: the latter may lead to innovation, or to failure. Mistakes associated with failure may subsequently generate innovation. In turn, innovative work behaviour may be an outcome of innovative learning (Høyrup, 2010, p.152).

Investigated in this paper is the role of information literacy in the learning of innovative work behaviour in the workplace, and the associated information behaviours that allow for innovative work behaviour to develop. The findings derive from an analysis of data gathered in twelve semi-structured interviews conducted within a Finnish organisation. Employee perceptions on recognition of the need to use information in the workplace, and to act upon this in support of the learning of innovative work behaviour, are explored. Interactions between people, information and innovation are key to the analysis. Practitioners in information and knowledge management may draw upon the findings to establish the key determinants of successful workplace learning of innovative work behaviour.

\section{Key concepts}

Three terms used throughout this paper merit definition as key concepts: (1) 'innovative work behaviour'; (2) 'information literacy'; and (3) 'information behaviour'. The term 'innovative work behaviour' is best defined with reference to innovation per se, and the role that employees play in creating innovations. Innovation may occur at the level of the individual, group, or organisation (West \& Farr, 1990, pp. 5-7), and can take many forms, e.g. product, process, organisational or marketing, technological, governance, conceptual (De Vries, Bekkers \& Tummers, 2015). Employees are a vital resource to innovation through 
their acquisition of up-to-date information, as well as experience-based knowledge, from interactions with materials, markets, customers and users (Høyrup, 2010, p.143). Taking these processes into account, and drawing upon West and Farr (1990), innovative work behaviour is defined here as 'the intentional generation and implementation of new and useful ideas within a role, a group, or an organisation'. Information literacy is the ability to think critically, make balanced judgements about information, and then use this information appropriately (e.g. ethically) to meet information needs (see, for example, Goldstein \& Whitworth, 2015, p.1; Johnston \& Webber, 2013). Those who are information literate, for example, are empowered to develop informed views and engage fully with society (Secker, 2018). Levels of information literacy are contingent upon information behaviour, i.e. the means by which individuals interact with (e.g. seek and use) information (Bates, 2010).

\section{LITERATURE: INFORMATION LITERACY, WORKPLACE INFORMATION LITERACY AND THE SCONUL MODEL}

It has been established that much information literacy research concerns studies conducted in educational settings (Williams, Cooper \& Wavell, 2014), often with a bias towards competence development in information seeking (Whitworth, 2014, p.7481). In response, there have been a number of recent calls to consider information literacy more extensively elsewhere (e.g. Goldstein \& Whitworth, 2015; Hall, Cruickshank \& Ryan, 2018 in press). These draw attention to the general value of training people in information handling, and in fostering environments to promote the effectiveness of information use (e.g. Goldstein \& Whitworth, 2015, p.1), as well as the opportunity to identify the complexities of information literacy across a variety of contexts. In terms of workplace information literacy, for example, there are contextual factors that may not come into play in educational learning. This is because, for example, workplace information literacy is embedded in practice (Lloyd, 2010, 2012) and is socially enacted (Lloyd, 2012, p.777). In addition, learning that underpins workplace information literacy is, more ad hoc, collaborative, multi-faceted, and informal than learning in educational environments (Cacciattolo, 2015; Goldstein \& Whitworth, 2015, p. 1).

Those keen to consider information literacy beyond the classroom have also explored the value of adopting and adapting extant information literacy models that were originally applied in educational settings, such as that advocated by SCONUL (2011). The SCONUL model was initially deployed by librarians and teachers as a method of delivering information skills to learners. Comprising 7 'pillars', it sets out skills/competencies and attitudes/understanding applicable to information use: identify, scope, plan, gather, evaluate, manage, present. This model has been acknowledged as useful in other contexts, and has been successfully adopted/adapted to generate new insight related to a range themes such as employability (Goldstein, 2015a) and democratic engagement (Hall, Cruickshank \& Ryan, 2018 in press).

\section{Research question}

Broad themes associated with the development of innovative work behaviour have been investigated in the past (e.g. Hauschildt, 1996). Equally, the relationship between workplace learning and innovation per se has been explored (e.g. Leong \& Anderson, 2012; Høyrup, 2010). However, the enhancment of innovative work behavour through workplace learning remains largely unexplored from the information science perspective. A wide exploration of the literature across multiple domains (e.g. workplace learning, organisational learning, and information and knowledge management) has highlighted the value of generating further understanding of contextual influencers of workplace learning development in relation to innovative work behaviour. One such factor is information literacy. Therefore, the research question that the study reported in this paper addresses is:

How does information literacy, and associated information behaviours, support successful workplace learning of innovative work behaviour?

\section{RESEARCH DESIGN AND METHODOLOGY}

\section{Study setting and sample}

This study used an explorative qualitative design informed by a constructivist approach to explore perceptions and actions of social factors (Flick, 2009, p.66-67), such as those involved in the learning process. Data were collected through the implementation of semi-structured interviews with twelve employees in a publically funded Finnish University. The use of semistructured interviews served two main purposes: (1) to explore themes that emerged from the participants with minimal direction for the researcher and; (2) to add depth and context to responses given from participants (Pickard, 2013). The participants were non-academic staff, employed in support services, e.g. library, education and research support, administration, finance, planning, communication. Three considered themselves to be leaders responsible for a service or department, and three managerial running services themselves while responsible to the leadership. The rest had no managerial responsibility. Three were male, and nine were female. All but one was of Finnish descent: the other was British. Five were aged 35-45, five 46-55 and two 56-65. It should be emphasised here that although the site for data collected was a university, the interviewees reflected on their daily roles as employees. Thus the interviews captured the nature of the workplace learning in an organisational setting (as opposed to educational learning in a classroom). 
The university operates through a strategy designed to concentrate on the core value of improvement between 2015 and 2020. Innovation is prominent in the strategy, and regarded as an anchor for the development of innovation. Data collection took place in December 2017. This timing was considered ideal for the purposes of the study because this was the mid-point of the implementation.

\section{Procedure}

Since the geographical location of the researcher and participating organisation differed, a facilitator shared study information with potential participants in Finland. The facilitator sent study information and researcher contact details to all departments within the support services to invite study volunteers to come forward. This opportunity sampling yielded twelve participants. Once each had given informed consent, the interviews were scheduled to take place at the university over a five-day visit to Finland.

The interview procedure was developed in English (the first or second language of all involved) to engage participants in discussions of how they learn to innovate best in the workplace, and explore factors influencing their learning and identification of success. 'Workplace learning' and 'innovative work behaviour' were explained by the researcher at the start of the interviews. Participants were asked to clarify their understanding of these terms and were able to refer back to the definitions at any point during the interview. The same procedure was carried out for definitions of 'information literacy' and 'information behaviour' before questions on these topics were posed. Initially, participants were asked 'How does information literacy play a role in learning to innovate?' Participants were then asked to indicate actions they carry out with information and how this supports the learning of innovative work behaviour: 'Could you explain the kind of things you do with information to help you learn to innovate?' Participants were then encouraged to talk about how such actions helped them to learn to innovate. If participants struggled to recall actions related to information use they were prompted using actions from the pillars of the SCONUL model (SCONUL, 2011). The interviews each lasted for around 30 minutes, with extra time for the participants to ask questions of the researcher before and after the interview. They were recorded on an audio device, and then transcribed to obtain twelve Word documents. The transcripts were imported into NVivo software for coding and analysis.

\section{Analysis}

The data were coded and analysed by one researcher, and the coding scheme was checked by two of the co-authors of this paper. The analysis was conducted in stages, using the thematic analysis procedure (Guest, MacQueen \& Namey, 2012), as shown in Figure 1. The initial stages of coding were guided by information literacy models to identify potential coding categories (e.g. information sharing, access, gathering, analysis, presentation). The process of data coding (stage 2) was repeated multiple times to ensure that all data were coded and potential themes could be categorised as they emerged. Saturation was reached when no new codes emerged from the interview transcriptions. In the final naming stage of the analysis (Stage 6) a narrative and working definition of the coded data were developed.

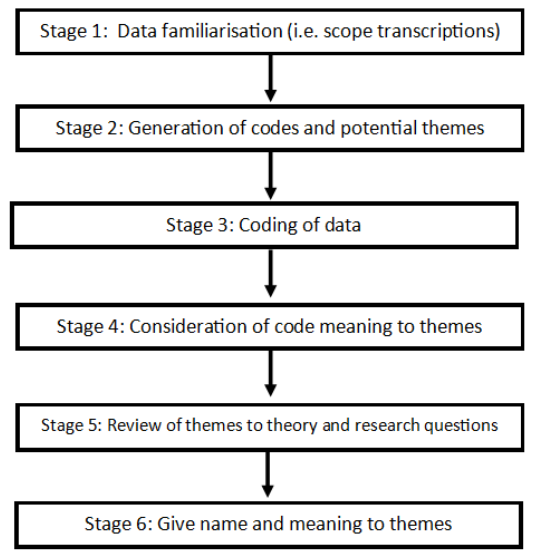

Figure 1. Stages of thematic analysis, adapted from Guest, MacQueen \& Namey (2012)

\section{RESULTS}

The participants discussed a range of views on the use of information to support their learning of innovative work behaviour: (1) the role of information literacy in the learning of innovative work behaviour; (2) the importance of information behaviours in learning to innovate and; (3) the use of different information sources in workplace learning. The sections that follow explore these themes in detail. 


\section{The role of information literacy in the learning of innovative work behaviour}

Nine participants explained that information is important for the development of innovative work behaviour through workplace learning. One noted:

Yes of course there is. I think you [as an employee] have to be very information literate in order to be a good learner in a workplace, yes and this helps to create new ideas. You have to be able to recognise what information is relevant for your job: what type of information you need and how you can get at that information (P5 - Librarian)

Two made explicit that information literacy is the first step towards recognising a need for workplace learning:

Well, it is relevant because that's like the first step that you need to learn something in a way (P11 - staff member in Planning and Development)

Similarly, two noted that information literacy helps give context to learning and presents a bigger picture of learning needs. It also helps to establish background information so that employees are aware of possible future requirements for change (e.g. the creation of new ideas) or a need for new learning:

I think it does because somehow it gives the bigger picture, somehow the context of learning things there in that sense so I think this is important (P9 - Project Coordinator)

Another gave an example of the importance of information needs recognition. She then questioned how the need for information focuses on the individual, and whether this could be supported (or improved) by sharing the request (i.e. the need for information) with others:

...since we're the communications department and there's always a need for more information and people [employees] always somehow experience that they didn't get enough information... we try to inform people [employees] about stuff and we're like 'How should we do this?' so the people know what they should know (P8 - staff member in Communication Services)

Similarly, the need for collective information literacy was also noted by other participants. Discussions centered on the organisation as a whole entity. Some employees may be able to recognise the information needs of other employees, but at the same time they need to understand the importance of sharing information in the process to help to innovate. Sharing information then helps observers to be aware of the information and decide whether it is important to their needs:

I don't know if I can say this but I think I'm quite good at recognising other people's need of information when it comes to being in the communications department. Then there are some people that I think they might organise a big event and then they don't realise that we have to inform people otherwise nobody knows about our fantastic event (P8 - staff member in Communication Services)

The participants also discussed the relationship between information literacy and the process of change. This appears to be evident when employees work within roles which may require frequent changes (an essential part to the development of innovative work behaviour). They highlighted the need for information to be recognised. Otherwise changes, such as those relevant to innovative work behaviour (in relation to process and organisational innovation suggested by De Vries, Bekkers \& Tummers, 2015, p.153), would not occur:

But I mean, now when you see it in front of you, so I mean this is really, really important. Because I mean, if we would just continue year after year without changing any things, so we wouldn't be this good, as we are (P3 - Departmental Coordinator)

\section{The importance of information behaviours in learning to innovate}

Information searching and access

The participants discussed information searching as an action in the development of workplace learning. Time spent searching is a barrier to learning: the employees explained that they find it difficult to find information they require due to the setup of the information source.

So looking for information on our website - that's something that they find difficult, and that's not because they are bad at searching (P10 - staff member in Education Services)

Information access is essential in order for employees to gather information quickly and generate new ideas, yet it was identified as challenge:

The whole access to information issue is challenging at the moment by everybody here (P2 - staff member in Research Services) 
If employees search for specific information for a length of time, and then cannot find it, this can hinder the process of innovative work behaviour. This is because as they do not have access to information that could help them generate new ideas:

So you sometimes think that "oh dear, the information is there." But they can't find it if it doesn't come in a really, really easy way, immediately when you put on Google or whatever you want to use. So if you don't get the right answer, it doesn't exist, because ...you don't have the patience to put so much time into finding information (P3 - Departmental Coordinator)

Information interpretation

The participants were of the opinion that information interpretation only helps them to learn if meaning can be added to the information, i.e. they can define the information, add context and can communicate this to another person. However, the addition of meaning to information takes time and requires employees to summarise information and break it down into smaller pieces first. The comment below was made by a participant who works within research services as a senior staff member and needs to interpret information frequently to then explain it to others.

I always try to somehow re-write it so it is easier and not just to send a link with 'read here' of course it is good to have that link because sometimes you need to read more, but also to somehow summarise what you need. It takes time but I have come to the conclusion that it is better and easier to open (P1 - staff member in Research Services)

Information analysis

There appears to be a direct relationship between information interpretation and information analysis. Employees analyse information (e.g. complex procedural documents) in order to understand the meaning and then interpret it:

I would say so yes, if I get a lot, I would analyse it and just pick out and try to maybe re-write it, then I can also put the link to the whole information, but I try to open it a bit. I work a lot with academia, and it is the same theory, they have no time for reading a lot when it comes to some new rules or something so it is easier to write something short, some lines, then they can read more if they want (P1 - staff member in Research Services)

The ability to analyse information supports employees in its interpretation. However, the time available to analyse the information is limited:

When I did my PhD ten years ago which was luxury time, I had four years to myself to gather the information and to analyse it and write it down. I don't have the time anymore...(P4 - Senior staff member in Education and Research Services)

The presentation of information

The analysis of information supports employees in presenting information to others, and possibly the sharing or development of new ideas as part of the innovation process. This then helps employees to discuss and create new ideas with others (i.e. the first stage of innovative work behaviour). A participant whose role focus is planning and development, and is required to make frequent presentations of information to others (e.g. when developing new ideas), said:

Then I use that to make a plan or suggestion or presentation for an idea or for the project plan (P11 - staff member in Planning and Development)

However, if information needs to be presented, employees have to ensure that the communication method is suitable for the audience in question (e.g. use appropriate language, demonstrate specific skills practically):

I suppose it depends on what kind of circumstances I'm in and who I'm talking to. Some people I realise prefer to read and so I put it in writing to them (P2 - staff member in Research Services)

\section{Information sharing}

Participants identified information sharing as a key activity to help people learn to innovate. However, this information sharing is only useful for employees when the information shared is relevant to the recipient:

Yes if it's relevant information for them somehow yes. And of course sharing information is really important and could be done more (P9 - Project Coordinator)

In some departments, information sharing is a requirement. Employees are asked to share information from events, or relevant information they have acquired elsewhere. In other departments information sharing is not expected from employees. However, participants in this study felt it is an important activity to help other employees learn. Employees share information to help them to discuss ideas and check how others complete certain tasks (e.g. process innovation). Similarly, sharing information helps employees to understand how to carry out their jobs more effectively (e.g. in relation to administrative or processes innovation) and this is especially important in the informal workplace context: 
Yeah. So we talk a lot together. Share the information. And then I mean check with the colleagues "How would you do that?" "Oh, we do it like this, we could do it like that." (P3 - Departmental Coordinator)

\section{The use of different information sources in workplace learning}

Five participants explained that people are an important information source, especially in cases where expertise is spread across the organisation:

It depends, since we are experts usually, I mean we are a small university and a small unit when I think about the resource services... there are not usually experts doing the same things, so for example we only have one innovation specialist, so there isn't anyone else who knows exactly that role (P1 - Senior staff member in Research Services)

People are information sources that can be accessed quickly, and are able to answer questions should the person seeking information require further clarification. A participant who works within Communication Services explained a preference for people as information sources:

So obviously networking is very important because if you find the right person to answer your question it's so much faster than to just try to look it up on the websites (P8 - staff member in Communication Services)

People are believed to be good information sources for the initiation of innovative work behaviour through idea exchanges, access to relevant (unknown) information, and new learning:

And also because their job is very similar to mine so then I can maybe steal some ideas and learn some things so I think that's a good thing for me. And then also since I'm here working with the press releases and media information, I also try to keep up with or maybe go to lunch with a journalist or somehow keep up with how they are working and how their work situation is developing and all these things (P8 - staff member in Communication Services)

The participants noted that workplace learning is successful when people can be contacted in multiple ways (e.g. telephone and online). Workplace learning takes place as the contact can be carried out a time and place suitable to those involved, overcoming geographical location difficulties experienced by staff in this organisation:

Because it's a national thing too. It's a challenge. And there are people in Helsinki and Tampere and all over Finland that are gathering, and taking part in these courses though the Net. With workplace learning is also that you can sit behind your desk and take part in discussions on the net. Connect and all those things. So yes (P6 - Librarian)

The participants failed to distinguish between internal and external personal contacts when they spoke about people as information sources. However, external bodies were frequently discussed by for their contribution to learning in the workplace. A variety were identified and were specific to particular departments. One participant noted:

In networks we have a network of chief librarians in Finland, so chief librarians of university libraries and that's a very good place to find information (P5 - Librarian)

External information sources help to bring in new knowledge. As a result, employees learn and are able to create new ideas to solve problems in the workplace. The comment below shows how external knowledge is vital to initiate changes in processes and procedures:

And then I also talked about it with our study psychologist, and then we were turning this idea round and looking at it and what could we do? And okay, so she already had some idea that she would... We need them to get to know each other (P7 - staff member in Administration)

The participants also emphasised the need for external knowledge to enter the organisation, and gave specific examples of how this is needed. In respect of the recruitment of new staff one participant said:

We always realise that when we can employ from outside, we get new knowledge - that is a very good thing because it tends to be, when you keep the same employees that the development gets very slow; people work the same way year in year out, and there is very little new learning (P12 - senior staff member in Financial Services)

Concerns with information sources are important to acknowledge, both in terms of the amount of information available and trustworthiness of sources. Four participants noted that the amount of information can hinder processes involved in workplace learning. This is due to time required to analyse and interpret the information. One noted:

Sure analyse it but my personal problem with the massive amount of information received is that we don't have the time to analyse it (P4 - senior staff member in Research and Education Services) 
Another referred to the need to critically analyse information, even in its vast amounts. The ability to handle large amounts of complex information is dependent on prior training and job roles:

I think in today's world there's too much information and how to have a critical standpoint to the flow of information...we have to be critical to the massive amount of information that comes from different sources (P4)

Trustworthiness of information is seen as a facilitator of learning for employees. For example, one participant suggested that she only uses information sources she trusts (e.g. published literature or blog posts written by familiar people). Another questioned reliability in relation to issues highlighted in the media (e.g. the use of fake news):

That is dependent upon what kind of information I need, but as I said in the beginning the most common thing for me as a person would be I tend to look at the sources I trust - that would be research literature, management literature, also blogs because I am interested in... Then again, trust is very important in this sense, and the trust not necessarily towards a person but trust to the source (P11 - staff member in Planning and Development)

\section{DISCUSSION}

The findings related above indicate that information literacy is a first step in the initiation of workplace learning in that it provides context for learning. There are five information behaviours that may support or hinder the learning of innovative work behaviour: (1) searching for and accessing information (2) information interpretation; (3) information analysis; (4) presentation of information and; (5) information sharing. In addition, the analysis shows the value of people as information sources, and highlights issues around information overload and trust.

The findings of this study relate to those found in prior research on the support of workplace learning in specific contexts (e.g. Fafeita \& Lloyd, 2012; Lloyd, 2010; Lloyd, 2012; Lloyd \& Somerville, 2006). The main contributions here relate to three themes: (1) information literacy skills as a prerequisite for workplace learning; (2) the role of information behaviours in supporting the learning of innovative work behaviour; and (3) information sources to support employees as they learn to behave innovatively.

\section{Information literacy skills as a prerequisite for workplace learning}

The findings show that the participants were able to contextualise information literacy and apply this to their own employment experiences with little effort, with acknowledgement of its importance in underpinning workplace learning. They also understood the importance of certain behaviours required for information literacy development in line with the SCONUL information literacy model (SCONUL, 2011). The collective nature of information literacy is evident in these findings, as has been identified in prior research. For example, Martin \& Steinkuehler (2010) note the informal learning that occurs in the social online context (p. 355), and Cacciattolo (2015) explores how informal learning forms part of workplace learning. This adds to the argument that collective elements of practice should be embedded in the development of information literacy definitions.

\section{The role of information behaviours in supporting the learning of innovative work behaviour}

Processes of searching for, and accessing, information are key contributors to the development of innovative work behaviour according to the findings generated from this study. This been previously noted in other research (e.g. Bruce, 1999; Li, Brake, Champion, Fuller, Gabel \& Hatcher-Busch, 2009). The participant discussions on organisational change processes have highlighted the need for information when a new direction is under consideration, and the negative impacts of a lack of information: the speed of change slows, or it may come to a standstill. Although prior research has investigated information behaviour and use in idea creation (e.g. Hauschildt, 1996), this does not address the innovative work behaviour process as a whole. In contrast the evidence here draws attention to the role of information in the process of change - first to help employees understand change, and second to support the creation of new ideas in the initial stages of the change process.

The findings related to information analysis within the workplace show that this may be supported, or hindered, by the nature of job roles. If it is accepted that workplace learning and innovative work behaviour result from reflecting on mistakes, then a lack of time for information analysis is a barrier (as well as a hindrance to general interpretation of information accessed).

Information sharing is shown to support innovative work behaviour in this context because it enables comparisons between organisations in terms of their achievements, procedures and processes (as related to process innovation discussed by De Vries, Bekkers \& Tummers, 2015, p.153), and facilitates the creation of new ideas to be created from knowledge gained in this way.

\section{The use of different information sources in workplace learning}

Early research on information literacy in the workplace evidenced the use of people as information sources. For example, Hertzum and Pejtersen (2000) suggested that engineers get most of their information from colleagues and internal reports, and Hertzum, Andersen, Andersen and Hansen (2002) found that people were a valued information source for software engineers. 
Specifically, engineers used colleagues to help them recommend information sources they could trust. The results from this study as outlined above are in line with these earlier findings.

The issue of trust in information sources as a key component in information source choice in this study replicates findings from earlier research (e.g. Allard, Levine \& Tenopir, 2008; Hertzum, Andersen, Andersen \& Hansen, 2002). Trust in information in the environment under scrutiny here is determined by the known provenance and associated reliability of information sources, and particularly the personal relationship between the users and creators of the information sources in question.

Information overload featured in the findings presented here, and is another theme covered extensively in the Information Science literature (e.g. Bawden \& Robinson, 2009). The most common consequence of information overload in respect of workplace learning is that it hinders productivity and efficiency of work. Participants in this research explained that the vast amount of information available is a barrier to their learning from it. The time required to analyse the large amount of information causes uneasiness and lowers confidence in information use. These findings are in line with recent research that suggests that information overload may influence the ability to search information effectively, and that people may not be aware of this (see Cleverley, 2017; Cleverley, Burnett \& Muir, 2017). This could lead to search tasks being terminated early and with a detrimental effect on organisational outcomes (Cleverley, Burnett \& Muir, 2017).

\section{Limitations and future research}

There are a number of limitations to the study presented here. First, it should be noted that during interviews the participants discussed examples of idea creation and the championing of such ideas, but examples of fully implemented ideas were not explained. Participants were able to talk about ideas they had generated, and ideas in the process of approval from leadership. However, none discussed examples of innovations that had been implemented and/or evaluated. This is most likely due to the timing of the interviews at the mid-point of an organisational strategy implementation. Further, the participants discussed innovations relevant to themselves, i.e. ideas they had generated or in which they had involvement. As such, this was the focus of conversations on their own innovative work behaviour, and did not reflect all innovative work behaviour processes in the organisation.

Further research could therefore explore the pillars of the SCONUL model quantitatively as related to innovative work behaviour processes. Any relationships identified could be then followed up by means of qualitative interviews to explore further the meaning of such relationships. This would give information on specific information processes required at each stage of innovative work behaviour, and emphasise the application of the SCONUL model in workplace processes. However, to date, a quantitative survey to specifically explore the SCONUL model as a measurement of information literacy has not been designed. Consideration of this, and the potential of model adaptation to fit workplace contexts, would be required as part of further research.

Finally, the use of study setting also reduces the generalisability of the findings to other organisatons and workplace contexts.

\section{Practical and theoretical recommendations}

Practitioners in information and knowledge management may draw upon the findings of these findings to identify key areas where information literacy can influence the learning of innovative work behaviour, and the contextual factors - such as information access and information sharing practices - that are important to this. Since this study has identified information literacy as a precedent of workplace learning of innovative work behaviour, practitioners may also wish to focus on the development of information literacy skills initially if improvements are to be made in how employees learn to behave innovatively. In terms of theory, this research has demonstrated the applicability of an educational information literacy model to the workplace context. To this end, academics could apply other information literacy models previously developed for higher education settings and apply the processes to the role of information literacy in the workplace. Such models may require some adaptation to reflect the differences of information literacy in education and information literacy in workplace settings. As a direct consequence new information literacy models and theoretical perspectives for the workplace may be developed.

\section{CONCLUSION}

Through an analysis of interview data collected from twelve employees working in support services of a Finnish University support services, it has been shown that (1) information literacy skills serve as a prerequisite for workplace learning; (2) information behaviours support the learning of innovative work behaviour and; (3) a variety of information sources support employees as they learn to behave innovatively. These findings add to extant knowledge in the field, while contributing new insight. Expanding on the results of this study would require further data to be collected on the specific processes involved in innovative work behaviour (e.g. recognition of the need for innovation, idea creation, idea championing and implementation) and the role of information literacy during each process. To this end, quantitative exploration of this relationship may identify specific relationship between processes and contributors and qualitative follow up could provide explanations as to the meaning of each relationship identified. 


\section{ACKNOWLEDGMENTS}

This work was supported by an Economic and Social Research Council [grant number: ES/J500136/1] and Skills Development Scotland as part of a collaborative +3 year PhD studentship. It was also supported by a John Campbell Trust student research bursary which provided funding for data collection to take place in Finland.

\section{REFERENCES}

Adhikari, J., Scogings, C., Mathrani, A., \& Sofat, I. (2017). Evolving digital divides in information literacy and learning outcomes: A BYOD journey in a secondary school. Internaltional Journal of Information and Learning Technology, 34(4), 290-306.

Allard, S., Levine, K., \& Tenopir, C. (2008). Design engineers and technical professionals at work: observing information usage in the workplace. School of Information Sciences Publications and Other Works. Retrieved from http://trace.tennessee.edu/utk_infosciepubs/3

Banek Zorica M., Spiranec S., Ogrizek Biskupic I. (2014). What is the employers stand on information literacy - researching employers on expected generic outcomes of their future employees. In: Kurbanoğlu S., Špiranec S., Grassian E., Mizrachi D., Catts R. (eds) Information Literacy. Lifelong Learning and Digital Citizenship in the 21st Century. ECIL 2014. Communications in Computer and Information Science, vol 492. Springer, Cham.

Bates, M. J. (2010) Information Behavior. In Encyclopedia of Library and Information Sciences, 3rd Ed. Marcia J. Bates and Mary Niles Maack, Eds. New York: CRC Press, vol. 3, pp. 2381-2391.

Bawden, D., \& Robinson, L. (2009). The dark side of information: overload, anxiety and other paradoxes and pathologies. Journal of Information Science, 35(2), 80-191.

Bruce, C. S. (1999). Workplace experiences of information literacy. International Journal of Information Management, $19(1), 33-47$.

Cacciattolo, K. (2015). Defining workplace learning. European Scientific Journal: Special Edition, 1, $243-250$.

Cleverley, P.H. (2017). Re-examining and re-conceptualising enterprise search and discovery capability: towards a model for the factors and generative mechanisms for search task outcomes. Robert Gordon University, PhD thesis. Held on OpenAIR [online]. Available from: https://openair.rgu.ac.uk/

Cleverley, P.H., Burnett, S., \& Muir, L. (2017). Exploratory information searching in the enterprise: a study of user satisfaction and task performance. Journal of the Association for Information Science and Technology [online], 68(1), 77-96. Available from: https://dx.doi.org/10.1002/asi.23595

Crawford, J., \& Irving, C. (2009). Information literacy in the workplace: a qualitative exploratory study. Journal of Librarianship and Information Science, 41(1), 29-38.

De Vries, H., Bekkers, V., \& Tummers, L. (2015). Innovation in the public sector: a systematic review and future research agenda. Public Administration, 94(1), 146-166).

Ellström, P-E. (2010). Practice-based innovation: a learning perspective. Journal of Workplace Learning, 22(1/2), 27-40.

Fafeita, J., \& Lloyd, A. (2012). Plating up information literacy as a social practice: a slice of the literature. Australian Academic and Research Libraries; 43(2), 92-101.

Flick, U. (2009). An introduction to qualitative research ( $4^{\text {th }}$ Ed). London, UK: SAGE.

Goldstein, S. (2015a). A graduate employability lens for the SCONUL seven pillars of information literacy. Retrieved from http://www.sconul.ac.uk/sites/default/files/documents/Employability_Lens_only_2015_0.pdf

Goldstein, S., \& Whitworth, A. (2015). DeVIL - Determining the value of information literacy for employers. Report retrieved from: https://www.informall.org.uk/wp-content/uploads/2015/11/DeVIL_report_final_draft_v05.pdf

Guest, G., MacQueen, K. M. \& Namey, E. E. (2012). Applied thematic analysis. Thousand Oaks, CA: SAGE Publications Ltd.

Hall, H., Cruickshank, P. \& Ryan, B. (2018, in press). Practices of community representatives in exploiting information channels for citizen democratic engagement. Journal of Librarianship and Information Science

Hauschildt, J. (1996). Innovation, creativity and information behaviour. Creativity and Innovation Management, 5(3), $169-178$.

Hertzum, M., \& Pejtersen, A.M. (2000). The information-seeking practices of engineers: searching for documents as well as for people. Information Processing \& Management, 36(5), 761-778.

Hertzum, M., Andersen, H.K. Andersen, V., \& Hansen, C.B. (2002). Trust in information sources: seeking information from people, documents, and virtual agents. Interacting with Computers, 14(5), 575-599.

Høyrup, S. (2010). Employee-driven innovation and workplace learning: basic concepts, approaches and themes. Transfer, 16(2) 143-154.

Johnston, B., \& Webber, S. (2003) Information literacy in higher education: a review and case study. Studies in Higher Education, 28(3), 335-352.

Leong, J., \& Anderson, C. (2012). Fostering innovation through cultural change. Library Management, 33(8/9), $490-497$.

Li, J., Brake, G., Champion, A., Fuller, T., Gabel, S., Hatcher-Busch, L. (2009). Workplace learning: the roles of knowledge accessibility and management. Journal of Workplace Learning, 21(4), 347-364. 
Lloyd, A. (2010). Information literacy landscapes: information literacy in education, workplace and everyday context. Chandos: London.

Lloyd, A. (2012). Information literacy as a socially enacted practice: sensitising themes for an emerging perspective of people-in-practice. Journal of Documentation 68, 772-783.

Lloyd, A \& Somerville, M. (2006). Working information. Journal of Workplace Learning, 18 (3), 186-198.

Martin, C., \& Steinkuehler, C. (2010). Collective information literacy in massively multiplayer online games. E-Learning and Digital Media, 7(4), 355-365.

Pickard, A.J. (2013). Research Methods in Information (2nd Ed.). London, UK: Facet Publishing.

Secker, J. (2018). The revised CILIP definition of information literacy. Journal of Information Literacy, S1(12), 56-158.

SCONUL. (2011). The SCONUL seven pillars of information literacy: core model for higher education. Retrieved form: https://www.sconul.ac.uk/sites/default/files/documents/coremodel.pdf

Tait, E., \& Edwards, R. (2016). Information literacy and information seeking of public sector managers in the Welsh Government. Library and Information Research, 40(123), 88-105.

West, M. A., \& Farr, J. L. (1990). Innovation at work. In M. A. West \& J. L. Farr (Eds.), Innovation and creativity at work: Psychological and organizational Strategies (pp. 1-37). Chichester, UK: Wiley.

Williams, D., Cooper, K., \& Wavell, C. (2014). Information Literacy in the Workplace: an annotated bibliography. Aberdeen: Robert Gordon University. Retrieved from https://pdfs.semanticscholar.org/39f2/63cb17222cacb8923a4628a8af2f61ab0aa5.pdf 